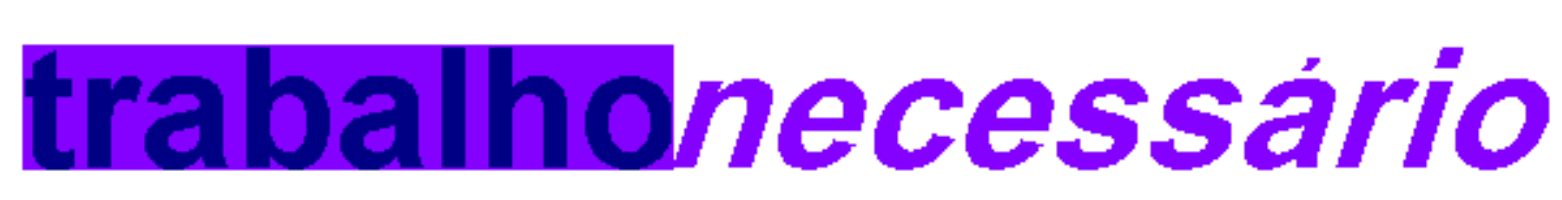

issn: $1808-799 \mathrm{X}$

ano 5 - número 5 - 2007

artigo

\title{
POSSIBILIDADES DA EDUCAÇÃO FÍSICA NA FORMAÇÃO DO TRABALHADOR
}

Jorge Oliveira dos Santos[i]

jorge42@terra.com.br.

O tema da educação pública tem ocupado amplos espaços nos meios de comunicação na atualidade. Aspectos como qualidade do ensino ministrado, universalização do acesso à escola, preparação para o trabalho e etc., têm sido utilizados para explicar parte do problema do desemprego, da disseminação da violência, da pobreza, como uma explicação baseada nos pressupostos da Teoria do Capital Humano.

Objetivamos, a partir desta totalidade, analisar as possibilidades do ensino médio inserido no panorama da preparação para a vida e para o trabalho e, ainda, oferecer uma possibilidade de superação da fragmentação verificada no trabalho escolar, pela via da educação física escolar, vinculando-a com a continuidade pós-escola. Verifica-se que quando o ciclo escolar se encerra, continua sendo necessária a preocupação com o nível mínimo de condicionamento orgânico geral para a manutenção da vida cotidiana, contra todos os desestímulos ofertados pelas comodidades tecnológicas. Trata-se aqui de explorar as possibilidades que esta disciplina oferece a partir de sua prática orientada dentro e fora da escola.

Outro ponto de importante inflexão em relação à educação física situa-se no fato de que grandes contingentes populacionais, sobretudo os que freqüentam as escolas públicas 
municipais e estaduais, mas não só elas, apenas dispõem desta possibilidade de vivenciar experiências corporais ao longo de toda a vida, no mais das vezes, motivados pelos incentivos televisivos, quer pelo discurso da promoção da saúde, quer pela promoção de grandes eventos esportivos. Parece-nos que estas experiências corporais, dentro ou fora da escola, permitem ao ser humano ver o mundo por pontos de vista diferentes quanto mais seus sentidos humanos forem desenvolvidos. (Marx, 2004) Propomos, então, uma reflexão através de uma linha condutora que perpassa necessariamente a unidade biológica de contato com o mundo: o corpo.

Observamos de outro lado, que com o passar do tempo, o aumento da população e a reestruturação do processo produtivo que alijou uma gama enorme de trabalhadores com baixa qualificação, acirrou de tal forma a busca por postos de trabalho que, parte das camadas médias passaram a disputar as vagas antes destinadas aos filhos das classes trabalhadoras. Neste panorama, grosso modo, se insere a rede federal de ensino tecnológico, de onde proferimos nossas argumentações.

Objetivamos o tratamento da questão da Educação Física Escolar e sua possibilidade contribuição na formação de técnicos do Ensino Médio. Tratá-la-emos pela mediação conceito marxiano de corpo, corroborado pelos estudos de Eagleton (1993). A investigaç se deu pelo materialismo histórico, método fundamental pelo posicionamento político que ‘ encerra, e pelo fato de ele proporcionar uma profunda investigação de um determina fenômeno em todas as suas determinações, com o fito a uma maior aproximação realidade, que dada a sua complexidade, não nos é permitido conhecê-la por complı Harnecker (1980). A diversidade de concepções empiricamente constatadas na prática Cefet de Química nos moveu, a partir do referencial teórico citado que se inscreve no Cam Trabalho Educação do Programa de Pós-Graduação em Educação da Universidade Fede Fluminense, no sentido de analisar as relações de produção e as contradições ali produzidi considerando uma totalidade social no qual a instituição está inserida.

\section{O CONCEITO DE POLITECNIA}

O conceito de politecnia implica uma apreciação anterior dos processos e d transformações decorrentes das lutas sociais próprias do capitalismo. No processo históri em que se desenrola esta disputa, observa-se a imposição de uma determinada visão a pa da qual se busca conformar as massas de um modo geral e a classe trabalhadora de mo particular à concepção burguesa de Homem, Sociedade e Estado. As instituições escolar refletem uma visão de mundo, normalmente hegemônica, o que, no entanto, não a exime um espaço de contradições possibilitadora de intervenções contra-hegemônicas. A divis social do trabalho estabelece duas propostas educacionais. Uma para os que terão aces às funções de planejamento e controle e outra para os que serão encarregados de execu os trabalhos, sem função de criação ou recriação teóricas. 
Portanto, a escola é um locus privilegiado de intervenção burguesa, e uma das principi vertentes de atuação e pressão ideológicas com o objetivo de alienar o trabalhador de $s$ saber e de seu corpo na luta pela produção de sua existência. Esta alienação se dá medida em que as classes burguesas utilizam-se de seu poderio econômico para cr consensos na superestrutura, plasmando instituições escolares, meios de comunicação geral, o Estado etc. tornando estranho ao trabalhador os resultados ou produtos de $\mathrm{s}$ própria atividade e à sua própria humanidade.(Machado, 1991)

O conceito de politecnia se contrapõe a esta concepção. Ele visa ao pleno desenvolvimer do indivíduo, quer para a produção de sua existência, quer para a fruição dos divers espaços sociais. Segundo Manacorda (2004), a proposição inicial de uma educaç politécnica foi feita por um industrial e filantropo, um dos socialistas utópicos, Robert Ow que realizou experiências no sentido de valorizar o trabalhador, criando uma forma organização do trabalho que restituísse a dignidade humana e a cultura aos operários e se filhos, e criticou a divisão do trabalho que provocava pobreza, ignorância, desperdícios todo tipo, delitos, miséria, grande fraqueza física e mental. Segundo ele, a contraposiç deste quadro seria dada por uma instrução geral que levasse a uma classe trabalhadoré um grau que seu nível estaria acima das classes passadas.

A proposta marxiana baseada em Owen concebia as atividades de trabalho e de educação como integrantes de um único processo, com articulação entre teoria e prática, pela educação politécnica, através das quais seriam transmitidos os princípios gerais e de carát€ científico de todo o processo de produção, além de uma iniciação no manejo das ferrament elementares das diversas profissões.

Esta concepção, em busca da omnilateralidade do indivíduo, previa: educação intelectu educação corporal, tal como se consegue com os exercícios de ginástica e militarı educação tecnológica que recolhe os princípios gerais e de caráter científico de todo processo de produção e, ao mesmo tempo, inicia as crianças e adolescentes no manejo ferramentas elementares dos diversos ramos industriais. (Machado, 1991).

Em tempos neoliberais, tal concepção se afigura completamente contra-conjuntural, no qua foco é o mercado, de forma fetichizada, como se não fosse movimentado pela ação $d$ homens, transferindo, inclusive, o mesmo sentido para a escola, a despeito do trabalhad que experimenta a concepção polivalente de formação, cuja preparação também leva $\epsilon$ conta o conhecimento não só de sua área específica, mas de todo processo produtivo. I entanto, esta preparação está restrita às limitações impostas pelas demandas dos interess econômicos imediatos. (Rodrigues, 1998). A proposta de educação politécnica represent um fio condutor para os anseios das classes trabalhadoras em sua organização polític profissional e partidária. 


\section{O TRABALHADOR E O SABER}

Para Marx, o processo de apropriação do saber pelos seres humanos ocorre em I ambiente contraditório e permeado por relações de poder, sendo a verda hegemonicamente imposta pelas classes dominantes. A constituição corporal dos indivídu e as relações que ela gera entre eles e o restante da natureza, no curso da produção de $s$ existência, são conseqüência de sua organização corporal, que por sua vez, depende forma de reprodução já encontrada anteriormente. A questão do corpo é um sério probler na visão de alguns autores. Eagleton (1993) considera uma tragédia como a dinâmica capitalismo transforma o corpo em cifra, através de suas extensões a que chamamos sociedade e tecnologia. A maneira como eles produzem determina como eles são, e a forı de intercâmbio entre eles se acha condicionada pela produção, que é determinada $p$ divisão social do trabalho.

O modo de produção capitalista provocou uma contínua modificação na forma de produ mercadorias e adicionalmente, o poder de persuasão, convencimento e coerção exercid pelo capital ao longo de seu desenvolvimento sedimentou uma cultura na sociedade em ge que deu suporte à alienação e mercadorização do trabalhador de seu conhecimento, de $\mathrm{s}$ corpo e do produto de seu trabalho.

\section{A TEORIA DO CAPITAL HUMANO (TCH)}

Com o objetivo de explicitar as concepções burguesas de Homem, Sociedade e Escola e, $\epsilon$ conseqüência, seu modus operandi, abordaremos algumas idéias elucidativas sobre utilização da Teoria do Capital Humano. A investigação executada por Frigotto (1986) exame das questões entre educação, trabalho e estrutura econômico-social capitalis demonstra que esta teoria é o objeto de estudo da economia da educação, e está ligadé produção de obras voltadas para a explicação dos vínculos entre a economia, o trabalho educação há alguns séculos. Em 1848, portanto, contemporaneamente ao desenvolvimer do marxismo, J. Stuart Mill, aprofundou o pensamento de Adan Smith, quando colocou que classe trabalhadora caberia uma educação que a tornasse apta a um julgamento sadio $d$ circunstâncias que a cercam. (J. Stuart Mill apud Frigotto, op. cit.1986).

Avançando um século, na década de 1950 a TCH foi objeto de sistemático desenvolvimen segundo Frigotto, objetivando a explicação das razões do desenvolvimento e da eqüida sociais. Ela concebe a educação como produtora de capacidade de trabalho potencializadora de renda, vinculando-se a uma segunda na medida em que esta se redui uma questão técnica, com o objetivo de a ajustar aos requisitos do mercado de trabalt (Ibid) Uma outra crítica é a de que, do ponto de vista funcionalista, a escola nada mais é que um aspecto da reprodução da divisão capitalista do trabalho. 
Para Frigotto o conceito de Capital Humano busca traduzir o montante de investimento q uma nação ou os indivíduos fazem, na expectativa de retornos adicionais futuros. investimento no 'fator humano' traduz-se num dos determinantes básicos para o aumento produtividade e elemento de superação do atraso econômico. Do ponto de vis microeconômico, constitui-se no fator explicativo das diferenças individuais de produtivida e de renda e, de mobilidade social"(idem).

Tal discussão assume importância fundamental, pois, segundo Frigotto, desde a década 1960, a política educacional brasileira ancorou-se em seus pressupostos, pois, a lógi imanente ao modo de produção capitalista é a mercadorização de tudo e de todos com 01 ao lucro. Pela ótica da $\mathrm{TCH}$, todos os indivíduos são livres e iguais no mercado de trocas portanto, podem vender e comprar o que querem, sendo o problema da desigualdac responsabilidade do próprio indivíduo.

Defendemos que à classe trabalhadora, deveria interessar desarticular tais concepções $n$ só por iniciativas pontuais, mas como classe a partir de uma avaliação de conjuntura, sain da aparência e superficialidade dos fenômenos, e mergulhando na análise e compreens das relações sociais da sociedade capitalista em que vivemos, identificando su contradições, para empreender esforços no sentido de superá-las.

Torna-se um movimento fundamental desvelar o caráter além de reprodutor da práti escolar, de sua dimensão técnica e política, na articulação dos interesses cont hegemônicos das classes dominadas, no movimento global pela transformação da socieda de classes. Esta escola é a escola de formação politécnica.

\section{A EDUCAÇÃO FÍSICA NO BRASIL - ANTECEDENTES}

A Educação Física se confunde com o ser humano desde quando o homem se diferenci dos animais pelo uso da razão e pela adequação da natureza a si, no trabalho diário pr manutenção de sua existência (Marx e Engels, 1998), e sempre esteve associada à vida todos os tempos.

O século XIX, segundo Soares (2002), merece atenção para a compreensão do proces evolutivo desta prática em relação à perspectiva de homem e sociedade, quando consolidou um "espírito capitalista" na Europa. Com efeito, a autora ressalta que es "espírito" difundiu uma crença desmedida no progresso, ancorado nos avanços científic Herdeira desta tradição científica e política que privilegia a ordem e a hierarquia desde $\mathrm{s}$ denominação inicial de Ginástica, a hoje chamada Educação Física foi e é compreendi como importante modelo de educação corporal que integra o discurso do poder. Soar afirma que existiram diversas tentativas de estender sua prática ao conjunto da populaç urbana, cada vez mais numerosa e potencialmente ameaçadora para os objetivos do capita 
A partir da Revolução Industrial, que provocou com maior intensidade o crescimento d cidades e a conseqüente diminuição dos espaços livres, a permanência de trabalhador numa mesma posição por longas horas, em virtude da especialização de seu ofício e próprio aumento das horas de estudo, dentre outros motivos, permitiu um novo alento prática da educação física, tendo sido criados diversos métodos ginásticos na época, cor os métodos alemão, austríaco, francês, dentre outros.

Destaque-se que cientistas como Georges Demeny, Etiene Jules Marey e Fernand Lagranc debruçaram-se em estudos de anatomia e fisiologia com o sentido de através da ginástic prescrever o gesto mais econômico ao trabalhador na indústria. Observou-se inclusive: tentativa de controlar o tempo do trabalhador fora do trabalho, para que ele se preservas ao máximo em favor de sua produtividade.

O Brasil concentrava a preferência em geral para o remo, no final do século XIX, e do futeb no século $X X$. A educação física continuou ganhando espaços sociais, e foi utilizada Estado Novo como instrumento ideológico quando tornou-se fundamental para solidificaç da ditadura instalada. Neste período, visava-se à formação de um homem de novo tipo, $\epsilon$ consonância com o pretendido pelo fordismo, para a obtenção de homens mais fortes, ág€ empreendedores em um espírito nacionalista. (Coletivo de Autores, 1992)

\section{EDUCAÇÃO FíSICA E FORMAÇÃO DO TRABALHADOR}

O trabalhador se constitui historicamente nas relações com seus semelhantes, e pelo trabalho se humaniza. Do nosso ponto de vista, a Educação Física será voltada para o trabalhador, no sentido ontológico, como vimos, focado na formação humana. Ratificamos esta posição, apoiado em Marx (1998), que equipara a prática da educação física na formação do trabalhador em geral as outras dimensões de preparação que compõem suas formações.

Nossa trajetória profissional e de nossa experiência no Cefet-Química, permitiu observaı importância que a prática regular da Educação Física representa na formação adolescentes e jovens para a vida social em geral e para o trabalho em particular. Seja cor uma ferramenta propiciadora de sociabilização dos alunos no ambiente em que se insere seja como uma ferramenta de sensibilização do 'corpo trabalhador', observamos que prática regular da Educação Física, na medida em que busca contribuir de forma sistemáti para a formação integral do homem, colabora igualmente para o enriquecimento $d$ propostas pedagógicas que visam diminuir os efeitos negativos da alienação produzida $p$ trabalho sob o modo de produção capitalista.

Oliveira (1985) aponta que a consciência do corpo que realiza todos os atos neste munc emoções, pensamentos, sexualidade, em atos motores, devem servir como um trabalho 
educação corporal que permita a cada um, olhar mais fundo em si mesmo, em busca saúde e da felicidade. Para o autor a Educação Física Escolar talvez seja a úni possibilidade acessível aos desassistidos, o $r$ não ocorre, posto que, paradoxalmen pratica-se a cultura da repressão corporal ao invés da conscientização corporal, em favor um Estado burguês sempre mais interessado em alienar do que conscientizar o cidadão. paradoxo em questão se explica em função de que o professor de educação física ter intenção de trabalhar a educação corporal de seus alunos, mas, termina por fazer o contrár atendendo funcionalmente os interesses do capital através de uma prática tecnicista.

Oliveira (1985), na mesma linha, constata como a ideologia das classes dominantes utilizada para colocar o real em zonas quase impenetráveis para a maioria das pesso: incutindo na consciência, no comportamento e no corpo delas, os princípios e conceil básicos que vão permitir a sua própria dominação. A consciência do corpo não e؛ desvinculada de uma Consciência de Classe, indispensável para uma necessária luta $k$ uma vida mais saudável, contra tudo que nos impeça de alcançá-la.

Quando um aluno executa um movimento num jogo, além de repercutir em todas dimensões de seu comportamento, veicula e introjeta determinados valores e normas comportamento, para além da aprendizagem motora, da aptidão física, desmistificando diferenças encobertas, ideologicamente, pela condição social.

Medina recomenda que o professor de Educação Física busque o entendimento de que o q determinará o uso que o indivíduo fará do movimento não será determinado pela condiç física ou habilidade desportiva, mas, sim, pelos valores e normas de comportamer introjetados pela condição econômica e pela posição na estrutura de classes de nos sociedade. Este todo caótico se verifica na materialidade das escolas brasileiras em geral pode traduzir uma prática irrefletida nos termos de uma sociedade "coisificada" como ate؛ Kosik (1995).

Neste sentido, Faraco (2001), observa que a Educação Física como componente curricu deve se organizar tendo como referencia o corpo humano, mais especificamente o corpo cada educando. Perseguimos a idéia de que a Educação Física, como prática social e cor disciplina escolar, compõe parte fundamental da educação dos sentidos humanos, tendo $\epsilon$ vista a perspectiva de uma formação omnilateral. (Eagleton,1993), (Saviani, 2003).

Para (Reis, 2004), a premissa marxiana de que o processo de humanização se faz no e pr trabalho, traz subentendida a idéia de um desenvolvimento que se move em todas dimensões vitais. Trata-se de um desenvolvimento que busca apropriar-se do mundo cor totalidade, sendo os sentidos, isto é, a visão, a audição, o olfato, o paladar, o tato, sentimento, o desejo, a ação, o amor, as ferramentas de apropriação dessa totalidade. $\mathrm{N}$ palavras de Marx, a apropriação da realidade humana, a maneira como esses órgãos comportam diante do objeto, constitui a manifestação da realidade humana (Marx, 2004). 
formação dos cinco sentidos é um trabalho de toda a história do mundo até aqui e é atrav deles que o trabalhador percebe o mundo e nele seu corpo".

Assumimos a tarefa de examinar a realidade da Educação Física que se impõe na esco sendo imperativo uma investigação empírica sobre como ela tem sido produzi materialmente (práxis) em seu cotidiano de modo que possamos analisar as mediações exercidas, bem como as contradições ali geradas. A forma como esta disciplina é trabalha numa instituição de formação profissional, denuncia a possibilidade da interferência de؛ prática no pleno desenvolvimento da formação deste trabalhador, dependendo do camin pedagógico proposto pela instituição. A carga horária dispensada à prática da Educaç Física, dentre outros, pode ser um indício deste caminho pedagógico.

$\mathrm{Na}$ década de 1990, os movimentos progressistas da Educação Física Brasileira q contestavam o modus operandi tecnicista e funcional praticado até aquele momento, produ: uma obra que ratificou o posicionamento político assumido por tais segmentos. Assim perspectiva da cultura corporal, no âmbito da Educação Física Escolar proposta pr "Coletivo de Autores" enfatiza as formas de representação simbólica de realidades histórič culturalmente vividas pelo homem. (Coletivo de Autores, 1992).

$\mathrm{Na}$ década atual, um estudo incorporou-se ao campo de discussões e de análise Educação Física no âmbito das crises estruturais do capitalismo. Demonstrou-se que a pa da necessidade de um trabalhador de novo tipo, em função do esvaziamento da catego trabalho, uma perda de importância desta prática social. Ao contrário do modelo fordis requeria-se agora, conhecimentos diferentes - abstração, comunicabilidade, criatividade etc., - características da acumulação flexível. A partir das novas demandas, a educação físi teria perdido sua importância, o que não ocorria fora da escola. (Nozaki, 2004)

Concordamos em parte. Aceitamos a hipótese do aumento de interesse para áreas $n$ formais da Educação Física, porém, assumimos, uma discordância e a subdividimos em di pontos. O primeiro baseado no fato de que, sim, houve um deslocamento de interesse $p$ Educação Física em geral, para as áreas não formais da cultura corporal, de fé comprovação empírica. O segundo, a hipótese de que a Educação Física Escolar n ganhou nem perdeu centralidade, quer nos modelos experimentados no Estado Novo, "milagre econômico" ou mesmo, na acumulação flexível. Nosso posicionamento tem ba empírica e suporte na legislação consultada desde as formulações das Leis Orgânicas Ensino Industrial até a última formulação da LDB 9394/96 com seus document complementares, e informações colhidas na cotidianidade das escolas e experiências $d$ professores da disciplina em questão.

A Educação Física Escolar brasileira, sempre esteve no mesmo lugar onde hoje se encont Desprezada ou incompreendida por parcelas de professores de outras disciplinas na esco e relegada a um plano secundário no plano maior da educação. Para a compreensão de 
quadro, suscitamos motivações de ordem material, ou de ordem profissional. À consideraçí que um professor de outra disciplina trabalhe em termos básicos, com giz, verifica-se qu€ "giz" do professor de educação física que é a bola ou material similar, com constância, I falte.

Embora o objetivo desta pesquisa não seja o de investigar tais eventos, sentimo-nos obrigação de fazer este registro para que a comunidade acadêmica possa deflagrar debatı no sentido de desvelar e aprofundar as razões pelas quais, apesar de leis e regulament، estes eventos não se consubstanciarem ao nível do concreto.

\section{A EDUCAÇÃO FÍSICA NO CEFET QUÍMICA}

Considerando o período das discussões de 1946 em diante, percebemos que a educaç física escolar quer seja como disciplinadora, promotora de saúde, formadora de um futı campeão ou contribuinte para a consecução da omnilateralidade do indivíduo, semr guardou uma obrigatoriedade. Independentemente dos objetivos que a ela se designem, ‘ se mantém oficialmente nos currículos. Contudo, sua prática acontece em atendimento a preceitos legais. Prova disso são os dispositivos utilizados para ratificar a obrigatoriedade sua prática, sintomaticamente, a saber: LDB 4024/61. Lei 5692/71, Decreto 69450/: Resolução 8/71, LDB 9394/96, Parecer CNE 376/97 e 5/97, Lei 10328/01, Lei 10793/03.

Nossas investigações a respeito do lugar da Educação Física na formação do trabalhador ensino médio da instituição levou-nos a consultar o maior número de informações disponívı da prática desta disciplina na instituição ao longo de sua história. Neste sentido, procedem à análise do material encontrado na forma de boletins $e$ atas do Conselho Representantes. Verificamos o atual Regulamento do Ensino Médio e Profissional médio pé o ano letivo de 2006, as Matrizes Curriculares de cinco cursos, e as ementas de algum disciplinas, atas de conselho pedagógico, documentos oficiais norteadores da educaç brasileira citados acima, além dos Decretos 2208/97 e 5154/04. É importante observar que modo geral, os textos legislativos e normativos guardam redações semelhantes, desde formulação das Leis Orgânicas do Ensino Industrial.

\section{CONCLUSÃO}

Baseamos nossas conclusões a partir do que entendemos como função social da escola, q é determinada socialmente numa sociedade dividida em classes e exerce o saber nı ambiente antagônico. Daí a importância da consciência do professor neste quadro e reconhecimento da educação como ato político, que implica escolhas possíveis mediant $\epsilon$ conhecimento dos grupos em disputa. $\mathrm{O}$ autor advoga que toda prática educativa possui ur dimensão política assim com toda prática política possui uma dimensão educativa. (Savia 2002) 
Constatou-se que a prática desta disciplina no interior da instituição está fortemente balizad por uma multideterminação de questões. Destaca-se entre elas, que o seu exercício mediante o estrito cumprimento da legislação em vigor, sugeriu que seria de outra forma na ausência da lei, enfatizando um plano secundário desta disciplina no ambiente escolar. A subsunção das concepções da instituição a lei maior do mercado de trabalho, apesar do reconhecimento interno da importância de sua prática na formação do trabalhador, traduziu se em uma contradição, merecedora de atenção em sua análise. A posição minoritária, contra-hegemônica, do alcance desta prática social, por um viés político não tem se exercitado apenas a partir de iniciativas individuais, desvinculada de uma discussão no grur específico e no grupo geral.

A exortação à participação política, emanada da fala dos entrevistados, nas instânci decisórias da instituição nos sugeriu que esta articulação não tem sido feita, demonstran um nível de despolitização em sentido mais amplo do grupo em questão. Consideroufundamental esta participação, no sentido de dar visibilidade a utilização desta disciplina formação daquele técnico.

De forma emblemática, ficou patente que esta despolitização tem seu lugar no âmbito própria instituição, quando apesar de todo o nível de discussões e de qualificação profissioı lá existente, não havia se produzido o Projeto Político Pedagógico. Este documento seric balizador dos caminhos pedagógicos sem os quais se incorporam as ideologias dominantes

Sugerimos uma tomada de posição do grupo de professores de Educação Física e instituição como um todo, da problematização da prática desta disciplina, como forma de explicitar um posicionamento político refletido e consistente sem o qual quaisquer tentativ resultarão infrutíferas. Acordamos com Faraco (2001) que diz que uma proposta curricu para a Educação Física no Ensino Médio tem de ter clareza de que o ser humano nãc composto de partes desconectadas. O intelectual, o emocional e o físico não são element que existem separadamente, mas em contínua interconexão. Sugerimos a problematizaç da situação dos trabalhadores na atual sociedade, em comparação com a vida dos própri alunos como futuros trabalhadores e a precarização iminente de seus direitos, alvo empresariado brasileiro, sintonizando-os neste cenário a partir de seus corpos.

Torna-se importante que o conjunto de suas atividades seja pensado na perspectiva concepção integral diminuindo a reprodução da ideologia dominante. Sabedores que $n$ está na escola a solução para os problemas e concepções que afligem, aliena e explora to uma estrutura social, consideramos, outrossim, este espaço possível de uma ação cont hegemônica em termos gramscianos.

As particularidades aqui observadas podem ser consideradas como mediações de universalidades de uma rede federal que envolve cerca de setenta instituições de ensino 
espalhadas ao redor do país, com graus variados, porém importantes, de inserção política $\epsilon$ social, o que a nosso ver, traz consideráveis reflexos na materialidade das relações sociais de produção e nos suscita a continuamente refletir e nos mover para a transformação desta realidade. Em acordo com Marx (2004), a história da sociedade burguesa seria transformad pelos seus produtos mais contaminados, pelos que carregam as marcas mais vivas da sua brutalidade. Nas condições em que os poderosos governam loucamente irrefreados, só os que não tem poder podem criar a imagem daquela humanidade que deverá chegar ao pod $\epsilon$ e, fazê-lo, transfigurar o próprio sentido deste termo.

\section{REFERÊNCIAS BIBLIOGRÁFICAS}

COLETIVO DE AUTORES. Metodologia do Ensino de Educação Física. São Paulo: Cortez, 1992.

EAGLETON, Terry. A Ideologia da Estética. Rio de Janeiro: Jorge Zahar Editor, 1993.

FARACO, Carlos Alberto. Educação Física. Considerações Gerais. In: KUENZER, Acácia (org.) Ensino Médio. Construindo uma proposta para os que vivem do trabalho. $2^{\underline{a}}$ edição. São Paulo: Cortez, 2001.

FRIGOTTO, Gaudêncio. A Produtividade da Escola Improdutiva. 2a edição. São Paulo: Cortez, 1986.

HARNECKER, Marta. Os Conceitos Elementares do Materialismo Histórico. São Paulo: Global Editora, 1980.

KOSIK, Karel. Dialética do Concreto. Rio de Janeiro: Paz e Terra, 1995.

MACHADO, Lucília Regina. Politecnia, Escola Unitária e Trabalho. São Paulo: Cortez: 1991. MANACORDA, M. História da Educação. Da Antiguidade aos nossos dias. São Paulo. Cortez, 2002.

MARX, K. Manuscritos Econômico-Filosóficos. São Paulo: Boitempo Editorial, 2004.

MARX, Karl; ENGELS, Friedrich. A Ideologia Alemã. 3ae edição. São Paulo: Martins Fontes, 1998.

NOZAKI, Hajime Takeuchi. Educação Física e Reordenamento do mundo do trabalho: Mediações da regulamentação da profissão. Niterói, maio de 2004. Tese de Doutoramento em Educação, Universidade Federal Fluminense.

Autores Associados, 1991.

OLIVEIRA, Vitor Marinho de. O que é Educação Física. São Paulo: Brasiliense, 1983. Educação Física Humanista. Rio de Janeiro: Ao Livro Técnico, 1985. Consenso e Conflito da Educação Física Brasileira. Campinas: Papirus, 1994.

REIS, Ronaldo Rosas. “Trabalho e Conhecimento Estético”. In: Revista Trabalho, Educação e Saúde. Rio de Janeiro: Fiocruz, 2004.

RODRIGUES, José. A Educação Politécnica no Brasil. Niterói: Eduff, 1998

SANTOS, Jorge O. Educação Física e Formação do Trabalhador. Dissertação de Mestrado. Niterói: UFF, 2006.

SAVIANI, Demerval. "O choque Teórico da Politecnia”. In: Trabalho, Educação e Saúde. Volume I, $\mathrm{n}^{\mathrm{o}} 1$, março de 2003. 
POSSIBILIDADES DA EDUCAÇÃO FISICA NA FORMAÇÃO DO TRABAL... Página 12 de 12

Escola e Democracia. Campinas: Autores Associados, 2002.

.SOARES, Carmem. Imagens da Educação no Corpo. Campinas, SP: Autores Associados, 2002.

[i] Mestre em Educação/UFF. Professor de Educação Física do Cefet de Química de Nilópolis - RJ e Profes؛ e Implementador de Educação Física da Secretaria Municipal de Educação de Duque de Caxias.

volta

file://C: Documents and Settings\Administrador\Meus documentos\Minhas Webs\NED... 11/9/2008 